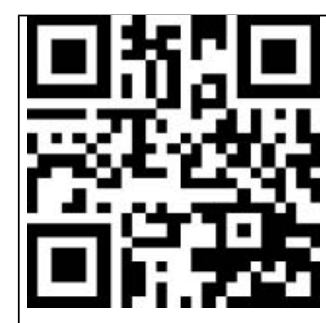

Scan to access more free content

${ }^{1}$ Cardiac Ultrasound Laboratory, Division of Cardiology, Massachusetts General Hospital, Harvard University, Boston, Massachusetts, USA

${ }^{2}$ Divisions of Cardiology and Clinical Epidemiology, Jewish General Hospital, McGill University, Montreal

Quebec, USA

${ }^{3}$ Division of Cardiac Surgery, Massachusetts General Hospital, Harvard University, Boston, Massachusetts, USA ${ }^{4}$ Department of Surgery and Center for Quality and Safety, Massachusetts General Hospital, Harvard University, Boston, Massachusetts, USA

\section{Correspondence to} Michael H. Picard, Cardiac Ultrasound Laboratory, Division of Cardiology, Massachusetts General Hospital, Harvard University, 55 Fruit Street, Boston, MA 02114, USA; mhpicard@partners.org

AWF and JA contributed equally.

Received 27 August 2012 Revised 6 November 2012 Accepted 6 November 2012 Published Online First 4 December 2012

\title{
Aortic sclerosis is associated with mortality and major morbidity in patients undergoing coronary artery bypass surgery
}

\author{
Aidan W Flynn, ${ }^{1}$ Jonathan Afilalo, ${ }^{2}$ Arvind K Agnihotri, ${ }^{3}$ Cristina Castrillo, ${ }^{1}$ \\ David M Shahian, ${ }^{3,4}$ Michael H Picard ${ }^{1}$
}

\begin{abstract}
Objective In this study, we aim to investigate the association between aortic sclerosis and mortality and major morbidity in patients with established coronary artery disease undergoing coronary artery bypass grafting (CABG).

Design Preoperative echocardiograms of consecutive patients undergoing isolated CABG between 2007 and $2009(n=1150)$ were analysed, excluding patients without an echocardiogram in the 30 days prior to surgery $(n=483)$. Using logistic regression, we evaluated the association between aortic sclerosis and inhospital mortality and major morbidity. Using Cox proportional hazards, the effect on long-term all-cause mortality was determined.
\end{abstract}

Setting Massachusetts General Hospital, Boston. Patients Patients undergoing isolated CABG between 2007 and 2009.

Interventions Analysis of echocardiograms.

Main outcome measures Inhospital mortality and major morbidity, and long-term all-cause mortality.

Results 627 patients were suitable for enrolment; 207 (33\%) had significant aortic sclerosis. These patients had higher rates of traditional cardiovascular risk factors. Significant aortic sclerosis was associated with an increased risk of inhospital mortality or major morbidity (OR 1.95; 95\% Cl 1.25 to 3.04). Following adjustment for baseline clinical and echocardiographic variables, the association remained significant (OR 1.90; 95\% Cl 1.15 to 3.11$)$. The HR for adjusted all-cause mortality was 2.52 (mean follow-up 2.7 years).

Conclusions Aortic sclerosis is a common finding in patients undergoing $C A B G$. In these patients, its presence is associated with a higher risk of inhospital mortality or major morbidity, and is associated with a higher risk of all-cause long-term mortality independent of other risk factors.

\section{INTRODUCTION}

Aortic sclerosis is a condition in which there is focal increased reflectivity and thickening of the aortic valve cusps noted on echocardiography, without evidence of adverse haemodynamic effects. ${ }^{1}$ In defining aortic sclerosis, many previous studies have included descriptions of calcification or bright echoes, ${ }^{2} 3$ and have reported peak Doppler velocities of $<2.5 \mathrm{~m} / \mathrm{s},{ }^{4} \leq 2.0 \mathrm{~m} / \mathrm{s},{ }^{3}{ }^{4}$ or $\leq 1.5 \mathrm{~m} / \mathrm{s}^{5}$ However, the use of Doppler velocities in describing aortic sclerosis is not universal. ${ }^{6-8}$ Semiquantitative grading scores have been proposed, but are not widely used. ${ }^{2}$

Aortic sclerosis is a common finding in many patient populations, and its presence increases with age. It has an estimated prevalence of $40 \%$ in patients over the age of $75 .^{9} 10$ Epidemiological studies have demonstrated an association between aortic sclerosis and cardiovascular events in asymptomatic patients, ${ }^{4}$ and in patients presenting with chest pain. ${ }^{2}$ In the Cardiovascular Health Study, ${ }^{4}$ aortic sclerosis was associated with a $35 \%$ increase in all-cause death. The echocardiographic substudy of the Losartan Intervention for Endpoint Reduction in Hypertension showed that aortic sclerosis was independently associated with a composite outcome of cardiovascular death, stroke or myocardial infarction over a median follow-up of 5 years. ${ }^{3}$ Despite the epidemiological studies that have reported an association between aortic sclerosis and adverse events, a population that has not yet been studied is patients with established coronary artery disease $(\mathrm{CAD})$ undergoing revascularisation.

In this study, we sought to determine the importance of aortic sclerosis in patients with severe CAD undergoing coronary artery bypass grafting $(\mathrm{CABG})$. As aortic sclerosis is associated with many risk factors for $\mathrm{CAD}$, the incidence in this specific subpopulation can be anticipated to be higher than the general population. Whether this prevalent condition has an association with the incidence of adverse events following CABG is uncertain.

\section{METHODS}

\section{Study population}

We identified 1150 consecutive patients who underwent isolated CABG at the Massachusetts General Hospital, Boston, USA between January 2007 and December 2009. Patients were excluded if no transthoracic echocardiogram was available within 30 days prior to surgery. The study was approved by the institutional review board of our institution.

\section{Echocardiographic analysis}

We analysed the latest echocardiogram performed within 30 days prior to CABG. Routine clinical echocardiograms were obtained using commercially available equipment (Sonos 5500, Sonos 7500 and iE33, Philips Medical Systems, Andover, Massachusetts, USA; Vivid 7, GE Healthcare, Milwaukee, Wisconsin, USA). Three observers blinded to the
To cite: Flynn AW, Afilado
Agnihotri AK, et al. Heart
$201399: 247-252$. 2013;99:247-252. 
clinical information analysed the echocardiographic data offline using commercially available software (Xcelera V.1.2; Philips Medical Systems). Each echocardiogram was analysed in duplicate by two observers. In cases where there was a discrepancy in grading aortic sclerosis, or any other parameter, the discrepancy was resolved by a senior cardiologist. All echocardiograms were performed and measured in accordance with the guidelines of the American Society of Echocardiography. 11-15

Aortic sclerosis was defined as irregular valve thickening, without evidence of outflow obstruction, as documented by a peak transvalvular velocity of $<2.5 \mathrm{~m} / \mathrm{s}$. Aortic sclerosis was subclassified according to the following scale: 0 -no thickening or hyper-reflectance; 1-slight hyper-reflectance; 2-mild hyperreflectance with thickening of $<2 \mathrm{~mm}$; 3-hyper-reflectance with thickening of 2-4 $\mathrm{mm}$; 4 -marked hyper-reflectance with thickening > $4 \mathrm{~mm}$. Grades $0-1$ were considered as absent aortic sclerosis; grade 2 was considered as mild aortic sclerosis; grades 3-4 were considered as significant aortic sclerosis. Because of the greater clinical utility of having dichotomised groups when evaluating a condition such as aortic sclerosis, we divided our groups into those with absent or mild aortic sclerosis (leaflet thickening of $<2 \mathrm{~mm}$ ), and those with significant aortic sclerosis (leaflet thickening of $\geq 2 \mathrm{~mm}$ ). A comprehensive set of additional echocardiographic parameters were assessed. Specifically, left ventricular volumes and ejection fractions (using the biplane method of disks), left ventricular mass and left ventricular diastolic function were assessed. Measurements of right and left atrial area, left atrial volume and pulmonary artery systolic pressure were obtained. Valvular regurgitation and stenosis were assessed using a multiparametric approach as reported by the echocardiography reader. Using multiple acoustic windows, the maximum jet velocity across the aortic valve was measured using continuous wave Doppler. Aortic valve area was calculated using the continuity equation.

\section{Patient data}

Demographic, clinical and procedural data were extracted from the Society of Thoracic Surgeons (STS) Adult Cardiac Surgery
Database. The STS definitions were applied for all covariates and end points used in this study. Vital status was extracted from the Social Security Death Index by way of the Research Patient Data Registry (Partners Healthcare, Boston, Massachusetts, USA). The primary outcome was a composite of inhospital mortality and major morbidity, defined by the STS as all-cause mortality, stroke, reoperation, renal failure, prolonged ( $>24 \mathrm{~h}$ ) ventilation or deep sternal wound infection. The secondary outcome was long-term mortality, defined as all-cause mortality occurring from the time of surgery to the end of follow-up.

\section{Statistical analysis}

Data are presented as mean $\pm \mathrm{SD}$. For the primary outcome, a multivariable logistic regression model was used to determine the effect of significant (Grades 3-4) aortic sclerosis on inhospital mortality or major morbidity. A multivariable Cox proportional hazards model was used to determine the effect on long-term allcause mortality. Pearson's correlation coefficient was used to calculate interobserver and intraobserver variability. Survival curves for all-cause mortality were constructed with the use of Kaplan-Meier estimates based on all available data. Patients were censored when they had the event of interest (mortality), or were lost to follow-up. Statistical analysis was performed with the STATA 12 software package (College Station, TX).

\section{RESULTS}

One thousand one hundred and fifty patients were identified as having isolated CABG during the study period. Four hundred and eighty-three were excluded due to no echocardiogram being performed at the study centre within 30 days of surgery. A further 37 patients were excluded due to the presence of peak transvalvular velocity $\geq 2.5 \mathrm{~m} / \mathrm{s}$, and three additional patients were excluded due to suboptimal visualisation of the aortic valve leaflets. There were 627 patients available for inclusion in the study (figure 1).

Of the 627 patients, 207 (33.0\%) had significant (Grades 3-4) aortic sclerosis. Of the remaining 420 patients, $177(28.2 \%)$ had
Figure 1 Derivation of the study population.

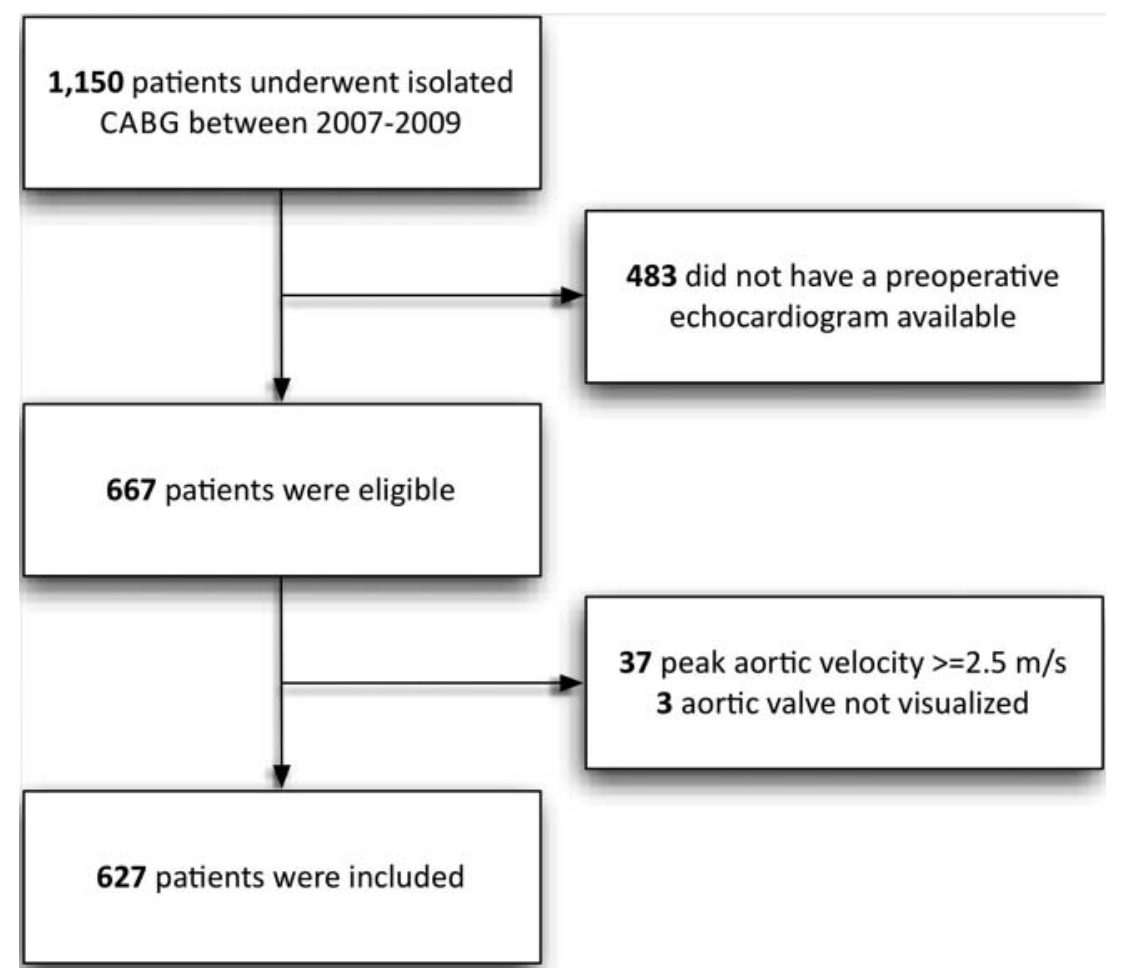


Table 1 Baseline characteristics

\begin{tabular}{|c|c|c|c|}
\hline & No significant aortic sclerosis $\mathrm{N}=420(67.0 \%)$ & Significant aortic sclerosis $\mathrm{N}=207(33.0 \%)$ & p Value \\
\hline Age (years) & $65.1 \pm 11.5$ & $70.8 \pm 9.4$ & $<0.01$ \\
\hline Female & $92(21.9)$ & $51(24.6)$ & 0.45 \\
\hline BMI $\left(\mathrm{kg} / \mathrm{m}^{2}\right)$ & $28.7 \pm 5.0$ & $28.8 \pm 5.3$ & 0.82 \\
\hline Hypertension & $357(85.0)$ & $187(90.3)$ & 0.07 \\
\hline Dyslipidaemia & $177(42)$ & $72(34.8)$ & 0.08 \\
\hline Diabetes & $139(33.1)$ & $87(42.0)$ & 0.03 \\
\hline Chronic kidney disease & $127(30.2)$ & $100(48.3)$ & $<0.01$ \\
\hline Chronic lung disease & $50(11.9)$ & $31(15.0)$ & 0.28 \\
\hline Peripheral arterial disease & $73(17.4)$ & $53(25.6)$ & 0.02 \\
\hline Prior stroke & $18(4.3)$ & 35 (16.9) & $<0.01$ \\
\hline Cardiac presentation: NSTEMI/STEMI & $126(42.6)$ & $61(41.0)$ & 0.7 \\
\hline Left main disease & $157(37.4)$ & $89(43.0)$ & 0.18 \\
\hline Number of diseased vessels & $3.7 \pm 0.6$ & $3.8 \pm 0.5$ & 0.04 \\
\hline Number of grafts & $3.3 \pm 1.1$ & $3.3 \pm 1.1$ & 0.99 \\
\hline STS predicted risk of mortality & $2.4 \pm 3.1$ & $3.5 \pm 3.7$ & $<0.01$ \\
\hline \multicolumn{4}{|l|}{ Inhospital outcomes } \\
\hline Mortality or major morbidity & $51(12.1)$ & $43(20.8)$ & $<0.01$ \\
\hline Mortality & $3(0.7)$ & $5(2.4)$ & 0.12 \\
\hline Stroke & $7(1.7)$ & $3(1.5)$ & 0.99 \\
\hline Renal failure & $9(2.1)$ & $9(4.4)$ & 0.1 \\
\hline Prolonged intubation & $35(8.3)$ & $26(12.6)$ & 0.09 \\
\hline Deep sternal wound infection & $7(1.7)$ & $5(1.5)$ & 0.85 \\
\hline Reoperation & $18(4.3)$ & $19(9.2)$ & 0.01 \\
\hline
\end{tabular}

BMI, body mass index; NSTEMI, non-ST-elevation myocardial infarction; STS, Society of Thoracic Surgeons; STEMI, ST-elevation myocardial infarction.

no aortic sclerosis (Grades 0-1) and 243 (38.8\%) had mild aortic sclerosis (Grade 2). The interobserver correlation for the grading of aortic sclerosis was $0.72(p<0.01)$ and the intraobserver correlation was $0.91(\mathrm{p}<0.01)$. Patients with significant aortic sclerosis were older, and had a higher prevalence of diabetes, peripheral arterial disease, chronic kidney disease and prior stroke. These patients also had a significantly higher STS-predicted risk of mortality. The baseline characteristics of all patients are shown in table 1 .

Compared with patients with absent or mild aortic sclerosis, patients with significant aortic sclerosis had a higher transvalvular velocity $(1.62$ vs $1.36 \mathrm{~m} / \mathrm{s} ; \mathrm{p}<0.01)$, lower dimensionless index $(0.64$ vs $0.75 ; \mathrm{p}<0.01)$ and higher indexed left ventricular mass $\left(98.7\right.$ vs $\left.92.3 \mathrm{~g} / \mathrm{m}^{2} ; \mathrm{p}<0.01\right)$. Left ventricular systolic function was similar between groups. Calcification of the mitral annulus was observed more frequently in patients with significant aortic sclerosis than without significant aortic sclerosis. Additional echocardiographic parameters are presented in table 2 .

Ninety-four episodes of mortality or major morbidity occurred during the index hospitalisation (table 1). The presence of significant aortic sclerosis was associated with an increased risk of the primary outcome (OR 1.95; 95\% CI 1.25 to 3.04), which is reflected in an absolute increase in event rate from $12.1 \%$ to $20.8 \%$. When adjusted for age, sex, peripheral arterial disease, diabetes, prior stroke and renal function, the association remained significant (OR 1.81; 95\% CI 1.14 to 2.89) To account for differences in the baseline echocardiographic features of both groups, we further adjusted for indexed left atrial volume, indexed left ventricular mass and aortic valve area. The association between significant aortic sclerosis and the primary outcome remained evident in the fully adjusted model
(OR: $1.90 ; 95 \%$ CI 1.15 to 3.11 ). Successively adjusted models are presented in table 3 .

In the Cox proportional hazards model, the HR for all-cause mortality in patients with significant aortic sclerosis was 3.32 (95\% CI 2.04; 5.42, p<0.001), with a mean follow-up of 2.7 years. The HR remained significantly elevated when adjusted for baseline clinical features (HR: 2.38, p=0.001) and for echocardiographic variables (HR: 2.52, $\mathrm{p}=0.001$ ) (table 4).

A Kaplan-Meier curve for adjusted all-cause mortality is shown in figure 2. The mean follow-up was 1156 days (range: 6-1802 days), with a median of 1168 days. There were no patients lost to follow-up for ascertainment of vital status.

\section{DISCUSSION}

Our study demonstrates that aortic sclerosis is a very common finding in patients with severe CAD undergoing isolated CABG. One third of patients were found to have moderate to severe ('significant') aortic sclerosis not meeting haemodynamic criteria for aortic stenosis, a finding which was associated with an increased risk of mortality and major morbidity in the shortterm and long-term follow-up periods. This increase in risk was independent of age, sex, known cardiovascular conditions and echocardiographic covariates such as aortic valve area and left ventricular mass.

In a population based cohort, ${ }^{4}$ and in a general cardiology cohort, $^{2}$ the prevalence of aortic sclerosis was $29 \%$ and $49 \%$ respectively, both of which are lower than the prevalence identified in the present study (72\%). Given the well-documented association between CAD risk factors and aortic sclerosis, it is not surprising that our selected patient population with diffuse CAD had such a high prevalence of aortic sclerosis. In our population, we observed that those with moderate to severe 
Table 2 Echocardiographic parameters

\begin{tabular}{|c|c|c|c|}
\hline & No significant aortic sclerosis $\mathrm{N}=420(67.0 \%)$ & Significant aortic sclerosis $\mathrm{N}=207$ (33.0\%) & p Value \\
\hline Transaortic peak velocity $(\mathrm{m} / \mathrm{s})$ & $1.36 \pm 0.28$ & $1.62 \pm 0.35$ & $<0.01$ \\
\hline Left ventricular outflow tract $(\mathrm{cm})$ & $2.15 \pm 0.20$ & $2.14 \pm 0.20$ & 0.56 \\
\hline Aortic valve area $\left(\mathrm{cm}^{2}\right)$ & $2.74 \pm 0.72$ & $2.33 \pm 0.68$ & $<0.01$ \\
\hline Aortic valve area indexed $\left(\mathrm{cm}^{2} / \mathrm{m}^{2}\right)$ & $1.38 \pm 0.32$ & $1.20 \pm 0.35$ & $<0.01$ \\
\hline Dimensionless index & $0.75 \pm 0.12$ & $0.64 \pm 0.15$ & $<0.01$ \\
\hline Left atrial volume index $\left(\mathrm{ml} / \mathrm{m}^{2}\right)$ & $29.9 \pm 10.8$ & $34.1 \pm 13.9$ & $<0.01$ \\
\hline $\mathrm{LV}$ end-diastolic volume index $\left(\mathrm{ml} / \mathrm{m}^{2}\right)$ & $105.6 \pm 39.8$ & $105.2 \pm 39.3$ & 0.91 \\
\hline LVEF $(\%)$ & $55.1 \pm 12.8$ & $55.0 \pm 12.2$ & 0.93 \\
\hline \multicolumn{4}{|l|}{ Diastolic filling } \\
\hline Normal & $172(41.0)$ & $52(25.1)$ & $<0.01$ \\
\hline Impaired & $140(33.3)$ & $74(35.8)$ & 0.53 \\
\hline Pseudonormal & $53(12.6)$ & $42(20.3)$ & 0.01 \\
\hline Restrictive & $39(9.3)$ & $22(10.6)$ & 0.61 \\
\hline N/A & $16(3.8)$ & $17(8.2)$ & 0.02 \\
\hline $\mathrm{LV}$ mass index $\left(\mathrm{g} / \mathrm{m}^{2}\right)$ & $92.3 \pm 23.4$ & $98.7 \pm 24.9$ & $<0.01$ \\
\hline Mitral annular calcification & $102(24.3)$ & $99(47.8)$ & $<0.01$ \\
\hline Right atrial area index $\left(\mathrm{cm} / \mathrm{m}^{2}\right)$ & $7.2 \pm 1.9$ & $7.6 \pm 2.3$ & 0.02 \\
\hline $\mathrm{RV}$ end-diastolic area index $\left(\mathrm{cm} / \mathrm{m}^{2}\right)$ & $8.1 \pm 2.2$ & $8.3 \pm 2.2$ & 0.28 \\
\hline RV fractional area change (\%) & $50.9 \pm 9.1$ & $49.3 \pm 9.7$ & 0.04 \\
\hline PASP $(\mathrm{mm} \mathrm{Hg})$ & $36.2 \pm 10.1$ & $40.9 \pm 13.3$ & $<0.01$ \\
\hline \multicolumn{4}{|l|}{ Aortic regurgitation } \\
\hline None-Trivial & $386(92.1)$ & $189(91.3)$ & 0.73 \\
\hline Mild & $29(6.9)$ & $18(8.7)$ & 0.42 \\
\hline Moderate & $4(1.0)$ & $0(0.0)$ & 0.99 \\
\hline \multicolumn{4}{|l|}{ Mitral regurgitation } \\
\hline None-Trivial & $256(61.3)$ & $114(55.1)$ & 0.14 \\
\hline Mild & $139(33.2)$ & $66(31.9)$ & 0.74 \\
\hline Moderate & $23(5.5)$ & $27(13.0)$ & $<0.01$ \\
\hline
\end{tabular}

LV, left ventricular, LVEF, left ventricular ejection fraction; N/A, not available; RV, right ventricular; PASP, pulmonary artery systolic pressure.

aortic sclerosis had a greater burden of risk factors (older age, diabetes, chronic kidney disease) and non-cardiac atherosclerotic vascular disease (peripheral arterial disease, cerebrovascular disease) when compared with those with no or mild aortic sclerosis. The association between aortic valve disease and CAD risk factors is likely due to these conditions sharing a similar pathophysiology. Oxidised low density lipoprotein, a well-established risk factor for CAD, has been observed in non-rheumatic stenotic aortic valves, ${ }^{16}$ and there is accumulation of apolipoprotein
$\mathrm{B}$ and $\mathrm{E}$ in early lesions of valvular aortic stenosis. ${ }^{17}$ There is evidence of an inflammatory cell infiltrate within lesions of aortic valve disease and CAD, and a portion of these cells produce osteopontin, leading to tissue calcification. ${ }^{18}$

Beyond its pathophysiological link to atherosclerosis, our data expand the findings of previous studies which have shown that aortic sclerosis carries prognostic significance as a marker of increased cardiovascular risk. ${ }^{19}$ In community-dwelling elderly patients with no known cardiovascular disease, there is an

Table 3 Logistic regression models for inhospital mortality or major morbidity in successively adjusted models

\begin{tabular}{|c|c|c|c|c|}
\hline & Unadjusted OR (95\% Cl) & $\begin{array}{l}\text { Model } 1 \\
\text { OR }(95 \% \mathrm{Cl})\end{array}$ & $\begin{array}{l}\text { Model } 2 \\
\text { OR }(95 \% \mathrm{Cl})\end{array}$ & $\begin{array}{l}\text { Model } 3 \\
\text { OR }(95 \% \text { Cl) }\end{array}$ \\
\hline Aortic sclerosis & 1.95 (1.25 to 3.04$)$ & 1.76 (1.11 to 2.77$)$ & 1.81 (1.14 to 2.89$)$ & $1.90(1.15$ to 3.11$)$ \\
\hline Age (years) & & $1.02(1.00$ to 1.04$)$ & 1.01 (0.99 to 1.04$)$ & 1.01 (0.99 to 1.04$)$ \\
\hline Female & & $1.06(0.63$ to 1.78$)$ & 0.93 (0.55 to 1.59$)$ & 1.35 (0.74 to 2.46$)$ \\
\hline Chronic kidney disease & & & 1.45 (0.84 to 2.50$)$ & 1.52 (0.86 to 2.66$)$ \\
\hline Prior stroke & & & 0.46 (0.18 to 1.14$)$ & 0.41 (0.16 to 1.05$)$ \\
\hline Peripheral arterial disease & & & 1.39 (0.82 to 2.35$)$ & 1.49 (0.87 to 2.55$)$ \\
\hline Diabetes & & & 1.07 (0.67 to 1.71$)$ & 1.07 (0.66 to 1.74$)$ \\
\hline Left atrial volume index $\left(\mathrm{ml} / \mathrm{m}^{2}\right)$ & & & & $1.02(1.00$ to 1.04$)$ \\
\hline Left ventricular mass index $\left(\mathrm{g} / \mathrm{m}^{2}\right)$ & & & & $1.01(1.00$ to 1.02$)$ \\
\hline Aortic valve area $\left(\mathrm{cm}^{2}\right)$ & & & & 1.69 (1.19 to 2.42$)$ \\
\hline
\end{tabular}

Model 1: adjusted for age, sex.

Model 2: adjusted for age, sex, cardiovascular conditions.

Model 3: adjusted for age, sex, cardiovascular conditions, echocardiographic variables. 
Table 4 Cox proportional hazards models for all-cause mortality at 2.7 years in successively adjusted models

\begin{tabular}{|c|c|c|c|c|}
\hline & $\begin{array}{l}\text { Unadjusted } \\
\text { HR }(95 \% \mathrm{CI})\end{array}$ & $\begin{array}{l}\text { Model } 1 \\
\text { HR }(95 \% \mathrm{CI})\end{array}$ & $\begin{array}{l}\text { Model } 2 \\
\text { HR }(95 \% \mathrm{Cl})\end{array}$ & $\begin{array}{l}\text { Model } 3 \\
\text { HR }(95 \% \mathrm{CI})\end{array}$ \\
\hline Aortic sclerosis & 3.32 (2.04 to 5.42$)$ & 2.91 (1.76 to 4.80$)$ & 2.38 (1.43 to 3.96$)$ & 2.52 (1.48 to 4.29$)$ \\
\hline Age (years) & & $1.03(1.00$ to 1.05$)$ & $1.01(0.98$ to 1.04$)$ & $1.01(0.99$ to 1.04$)$ \\
\hline Female & & $1.14(0.65$ to 1.99$)$ & $0.86(0.49$ to 1.51$)$ & $1.11(0.59$ to 2.09$)$ \\
\hline Chronic kidney disease & & & 2.70 (1.50 to 4.87$)$ & $2.60(1.43$ to 4.71$)$ \\
\hline Prior stroke & & & 1.09 (0.55 to 2.16$)$ & $0.88(0.42$ to 1.81$)$ \\
\hline Peripheral arterial disease & & & 1.85 (1.12 to 3.06$)$ & 2.12 (1.27 to 3.56$)$ \\
\hline Diabetes & & & $2.48(1.50$ to 4.12$)$ & $2.43(1.45$ to 4.08$)$ \\
\hline Left atrial volume index $\left(\mathrm{ml} / \mathrm{m}^{2}\right)$ & & & & 1.01 (0.99 to 1.04$)$ \\
\hline Left ventricular mass index $\left(\mathrm{g} / \mathrm{m}^{2}\right)$ & & & & 1.01 (1.00 to 1.02 ) \\
\hline Aortic valve area $\left(\mathrm{cm}^{2}\right)$ & & & & 1.51 (1.03 to 2.22$)$ \\
\hline
\end{tabular}

increased risk of cardiovascular death among those with aortic sclerosis. ${ }^{4}$ In patients with evident cardiovascular disease, aortic sclerosis was also associated with adverse cardiovascular events, although this effect was attenuated after adjustment for baseline factors. A further study of a preoperative cohort of patients undergoing vascular surgery demonstrated that aortic valve calcium was independently associated with the outcomes of 30 day cardiovascular events and long-term mortality. ${ }^{20}$ However, aortic sclerosis did not have a significant association with the outcomes-rather the significance of the observations was driven by the event rate in those with aortic stenosis. In our study of patients with extensive coronary disease undergoing CABG, aortic sclerosis was associated with postoperative mortality or major morbidity in unadjusted and adjusted analyses.

The explanation for the association between aortic sclerosis and adverse events has not been fully elucidated. It has been proposed that disease progression from aortic sclerosis to haemodynamically significant aortic stenosis may be responsible. ${ }^{21}$ In this study, we excluded patients with aortic stenosis, and our primary endpoint was adjudicated during the index hospitalisation, thus removing the possibility of disease progression as an explanation for the findings. It has also been suggested that aortic sclerosis serves to identify patients with subclinical disease, thus predicting adverse events in those without established disease. ${ }^{22}$ As we included only patients with clinically apparent CAD, with

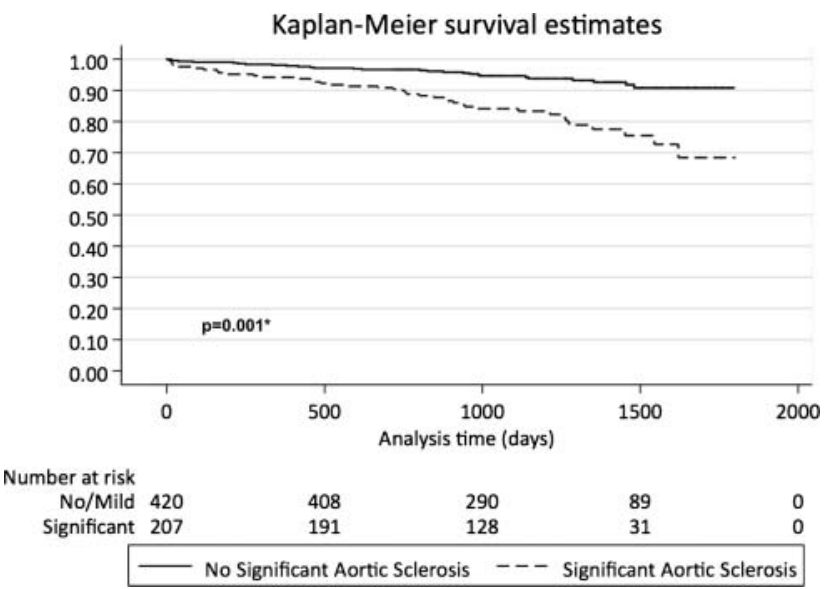

Figure 2 Event free survival in patients with and without significant aortic sclerosis estimated by Kaplan-Meier analysis. a similar burden of CAD in both groups (with respect to the number of diseased vessels, incidence of left main disease and numbers of vessels bypassed), this scenario is unlikely. It has been hypothesised that inflammation and endothelial dysfunction are mechanistically involved in the adverse events associated with aortic sclerosis. ${ }^{23}$ Data on this is compelling, but a definite association has not yet been established. This study was not designed to support or contradict this potential mechanism.

In this study, we observed an incidence of mortality or major morbidity of $12 \%$ in patients without significant aortic sclerosis, and of $21 \%$ in patients with significant aortic sclerosis. Following correction for covariates that differed between groups, significant aortic sclerosis remained strongly associated with the primary outcome. Multiple sensitivity analyses were performed to adjust for additional covariates and no evidence of residual confounding was observed. Specifically, despite the difference in primary outcome being largely due to reoperation, intubation and renal failure, adjusting for number of diseased vessels, pre-existing lung disease and chronic kidney disease did not impact on the contribution of significant aortic sclerosis to outcome.

Our study has some important limitations. First, due to the observational nature of this study design, there is a possibility of unmeasured confounders which may have introduced some bias. As mentioned above, however, we did adjust for several cardiovascular conditions and risk factors, as well as echocardiographic parameters, and did not observe any indications of important confounding. Second, we evaluated the association between aortic sclerosis and the broad outcome of mortality and major morbidity, the latter of which incorporates non-cardiac morbid events, which may not have a direct pathophysiological link with aortic sclerosis. However, although this outcome is broad, it is a well-established metric of overall events, and there is often a causative link between seemingly non-cardiac morbid events and cardiac dysfunction. For example, pump failure may result in renal dysfunction, and inflammatory responses postoperatively may result in impaired wound healing. Nonetheless, this study was not designed to test the mechanistic basis underlying the association between aortic sclerosis and adverse events, and a causal link cannot be proven. Third, we did not collect data on echocardiograms and aortic valve replacement procedures after the index CABG, and could not ascertain whether there was progression of aortic sclerosis to significant stenosis. Given the relatively short timeframe and expected progression of aortic 
stenosis based on prior studies, this possibility remains remote. Finally, there are no interventions available to ameliorate the risk associated with aortic sclerosis. Although benefits in clinical outcomes were observed in a study of lipid lowering therapy in patients with aortic stenosis, ${ }^{24}$ the use of statins did not reduce the rate of progression of valve disease. ${ }^{25}$ Therefore, the presence of significant aortic sclerosis should raise awareness of the increased risk of inhospital adverse events, although this may be a non-modifiable risk factor.

In conclusion, significant aortic sclerosis is present in a large proportion of patients undergoing isolated CABG, and its presence is associated with an increased incidence of inhospital mortality and major morbidity, and all-cause mortality in long-term follow-up. Future research is warranted to explore the mechanistic basis of this association and the value of therapeutic interventions.

Contributors Each author contributed to study design and manuscript preparation. AWF, JA and CC performed all data collection and analysis. MHP was the senior cardiologist who adjudicated on discrepant results. All authors approved the final draft of the manuscript.

Funding None.

Competing interests None.

Ethics approval Institutional Review Board.

Provenance and peer review Not commissioned; externally peer reviewed.

Data sharing statement This original research article was prepared from a database that was established by the authors and is accessible to all listed authors. This database is controlled by the senior author (MHP) and future work using this database will be at his discretion.

Additional data All data relevant to this article is presented in the article.

\section{REFERENCES}

1 Baumgartner $\mathrm{H}$, Hung J, Bermejo J, et al. Echocardiographic assessment of valve stenosis: EAE/ASE recommendations for clinical practice. J Am Soc Echocardiogr 2009;22:1-23

2 Chandra HR, Goldstein JA, Choudhary N, et al. Averse outcome in aortic sclerosis is associated with coronary artery disease and inflammation. J Am Coll Cardiol 2004:43:169-75.

3 Olsen MH, Wachtell K, Bella JN, et al. Aortic valve sclerosis and albuminuria predict cardiovascular events independently in hypertension: a losartan intervention for end-point reduction in hypertension (LIFE) substudy. Am J Hypertens 2005:18:1430-6.

4 Otto CM, Lind BK, Kitzman DW, et al. Association of aortic-valve sclerosis with cardiovascular mortality and morbidity in the elderly. N Engl J Med 1999;341:142-7.

5 Aronow WS, Ahn C, Shirani J, et al. Comparison of frequency of new coronary events in older subjects with and without valvular aortic sclerosis. Am J Cardiol 1999;83:599-600, A598.

6 Kizer JR, Wiebers DO, Whisnant JP, et al. Mitral annular calcification, aortic valve sclerosis, and incident stroke in adults free of clinical cardiovascular disease: the Strong Heart Study. Stroke 2005;36:2533-7.
7 Taylor HA Jr, Clark BL, Garrison RJ, et al. Relation of aortic valve sclerosis to risk of coronary heart disease in African-Americans. Am J Cardiol 2005;95:401-4.

8 Fox CS, Larson MG, Vasan RS, et al. Cross-sectional association of kidney function with valvular and annular calcification: the Framingham heart study. J Am Soc Nephrol 2006;17:521-7.

9 Stewart BF, Siscovick D, Lind BK, et al. Clinical factors associated with calcific aortic valve disease. Cardiovascular Health Study. J Am Coll Cardiol 1997;29:630-4.

10 Lindroos M, Kupari M, Heikkilä J, et al. Prevalence of aortic valve abnormalities in the elderly: an echocardiographic study of a random population sample. J Am Coll Cardiol 1993:21:1220-5

11 Schiller NB, Shah PM, Crawford M, et al. Recommendations for quantitation of the left ventricle by two-dimensional echocardiography. American Society of Echocardiography Committee on Standards, Subcommittee on Quantitation of Two-Dimensional Echocardiograms. J Am Soc Echocardiogr 1989;2:358-67.

12 Lang RM, Bierig M, Devereux RB, et al. Recommendations for chamber quantification: a report from the American Society of Echocardiography Guidelines and Standards Committee and the Chamber Quantification Writing Group, developed in conjunction with the European Association of Echocardiography, a branch of the European Society of Cardiology. J Am Soc Echocardiogr 2005;18:1440-63.

13 Nagueh SF, Appleton CP, Gillebert TC, et al. Recommendations for the evaluation of left ventricular diastolic function by echocardiography. J Am Soc Echocardiogr 2009:22:107-33.

14 Rudski LG, Lai WW, Afilalo J, et al. Guidelines for the echocardiographic assessment of the right heart in adults: a report from the American Society of Echocardiography endorsed by the European Association of Echocardiography, a registered branch of the European Society of Cardiology, and the Canadian Society of Echocardiography. J Am Soc Echocardiogr 2010;23:685-713.

15 Zoghbi WA, Enriquez-Sarano M, Foster E, et al. Recommendations for evaluation of the severity of native valvular regurgitation with two-dimensional and Doppler echocardiography. J Am Soc Echocardiogr 2003;16:777-802.

16 Olsson M, Thyberg J, Nilsson J. Presence of oxidized low density lipoprotein in nonrheumatic stenotic aortic valves. Arterioscler Thromb Vasc Biol 1999:19:1218-22.

17 O'Brien KD, Reichenbach DD, Marcovina SM, et al. Apolipoproteins B, (a), and E accumulate in the morphologically early lesion of 'degenerative' valvular aortic stenosis. Arterioscler Thromb Vasc Biol 1996;16:523-32.

18 O'Brien KD, Kuusisto J, Reichenbach DD, et al. Osteopontin is expressed in human aortic valvular lesions. Circulation 1995;92:2163-8.

19 Gharacholou SM, Karon BL, Shub C, et al. Aortic valve sclerosis and clinical outcomes: moving toward a definition. Am J Med 2011;124:103-10.

20 Valentijn TM, Hoeks SE, Bakker EJ, et al. Influence of aortic valve calcium on outcome in patients undergoing peripheral vascular surgery. Am J Cardiol. 2012;110:1195-9.

21 Otto CM, Burwash IG, Legget ME, et al. Prospective study of asymptomatic valvular aortic stenosis. Clinical, echocardiographic, and exercise predictors of outcome. Circulation 1997:95:2262-70.

22 Agmon Y, Khandheria BK, Meissner I, et al. Aortic valve sclerosis and aortic atherosclerosis: different manifestations of the same disease? Insights from a population-based study. J Am Coll Cardiol 2001;38:827-34.

23 Poggianti E, Venneri L, Chubuchny V, et al. Aortic valve sclerosis is associated with systemic endothelial dysfunction. J Am Coll Cardiol 2003;41:136-41.

24 Rossebø $A B$, Pedersen TR, Boman $K$, et al. Intensive lipid lowering with simvastatin and ezetimibe in aortic stenosis. N Engl J Med 2008;359:1343-56.

25 Chan KL, Teo K, Dumesnil JG, et al. Effect of Lipid lowering with rosuvastatin on progression of aortic stenosis: results of the aortic stenosis progression observation: measuring effects of rosuvastatin (ASTRONOMER) trial. Circulation 2010;121:306-14. 